\section{Marx según Marzoa}

Marx according to Marzoa
Jordi Soler Alomà ${ }^{1}$

Universitat Pompeu Fabra

Recibido: 15.10 .2021

Aceptado: 12.12.2021

\title{
Resumen
}

El sentido de este artículo es el de mostrar, mediante del análisis de la obra principal de F. M. Marzoa, cómo incluso a través de los autores que con mayor rigor enfrentan la lectura de la obra de Marx, se filtra, de diversos modos, parte del material conceptual alienado que constituye la ideología, así como versiones tópicas de determinadas desviaciones del pensamiento marxiano. Lo que vale para Martínez Marzoa (quien, a juicio del autor del presente artículo, es uno de los mejores intérpretes de Marx) vale, también, para Althusser, en parte para la "escuela de Frankfurt" y otras corrientes postmodernas.

Palabras clave: alienación, capital, Das Kapital, Karl Marx, estructura, sistema, teoría de sistemas, economía política.

\section{Abstract}

The purpose of this article is, through the analysis of the main work of FM Marzoa, to show how even through the authors who most rigorously confront the reading of Marx's work, part

1jsoler84@xtec.cat

https://orcid.org/0000-0003-2487-6093

Volumen 2. Número 1. Enero - Junio 2022 
of the alienated conceptual material that constitutes ideology is filtered in various ways, as well as topical versions of certain deviations from Marxian thought. What is valid for Martínez Marzoa (who, in the opinion of the author of this article, is one of the best interpreters of Marx) is also valid for Althusser, in part for the "Frankfurt school" and other postmodern currents.

Keywords: alienation, capital, Das Kapital, Karl Marx, structure, system, systems theory, political economy.

\section{Introducción}

Felipe Martínez Marzoa (Vigo, 1943) es un filósofo español, catedrático de la UB, cuyo trabajo intelectual se caracteriza por su originalidad y audacia. Su lectura del pensamiento de Karl Marx es una de las más interesantes que se pueden encontrar. En 1982 presentó su tesis doctoral sobre "La teoría del valor de Marx en la filosofía moderna". Más adelante (1983) publicó La filosofía de El Capital de Marx, que era una reelaboración de su tesis doctoral.

El mérito de esta obra fue, por un lado, llamar la atención sobre el "Marx filósofo" en una época dominada por el postmodernismo, y, por el otro, situar la obra de Marx en el lugar que le corresponde, criticando la falta de rigor académico con la que es tratada al mismo tiempo que denunciando lo que él llama el "vicio antifilológico" con respecto a la obra de dicho autor. También es mérito suyo contribuir a acotar el núcleo del pensamiento marxiano y diferenciarlo de lo que o bien no pertenece a éste "núcleo" o bien no pertenece al pensamiento de dicho autor. Prácticamente la mitad de la obra mencionada está dedicada a estas dignas empresas; sin embargo, por lo que hace al análisis de Das Kapital, la obra lleva a cabo un breve recorrido por la parte más esencial y se centra en lo que será la tesis de Marzoa sobre Marx: a saber, que el precio que pagará éste por superar a Hegel será el abandono de la perspectiva histórica parar centrarse en una única "figura": la estructura de la sociedad moderna. Esta es la tesis

que aparece como esbozo en dicha obra, pero sobre la que se centra ampliamente en su posterior trabajo sobre Marx, inserto en su Historia de la Filosofía (1994). Es en este texto 
donde concentramos nuestro análisis, cuyo objetivo es poner de relieve los aciertos que contiene como lo que, a nuestro entender, no lo son.

El sentido de este artículo es mostrar cómo, incluso en los autores más serios respecto de la lectura de la obra de Marx, se filtra, de diversos modos, parte del material conceptual alienado que constituye la ideología. Lo que vale para Martínez Marzoa (quien, a juicio del autor de estas líneas, es uno de los mejores intérpretes de Marx) vale, también, para Althusser, en parte para la "escuela de Frankfurt" y otras corrientes postmodernas.

\section{Marx vs Hegel}

El autor empieza su argumentación planteando una historiografía marxiana, dentro de la cual Marx establece una aporía por lo que hace a su asunción de Hegel, a saber: “...negándose a aceptar que el ser tenga lugar sólo como la autosupresión de la reflexión y asumiendo algo así como que, si todo está bien en la lógica de Hegel, entonces habrá quedado integrado en el modelo hegeliano el concepto de ser mas no el ser." (Marzoa, 2003, 232). En otras palabras, Hegel se queda con la Idea Absoluta y desestima lo material (como ya era sabido antes de Marx).

Según Marzoa (loc cit), no es posible la noción de dialéctica hegeliana sin la asunción de la autosuficiencia del concepto; para él, dicha imposibilidad "será lo que se ponga de manifiesto también en el desarrollo de la obra de Marx" (loc cit). Marzoa no cree que Marx tenga relación con la "dialéctica materialista" o el "materialismo dialéctico". En este sentido, Marzoa critica, acertadamente, la interpretación según la cual la "fenomenología del espíritu" o la "experiencia de la conciencia" sería en Marx la "historia real", en la cual las "figuras de la conciencia" o "figuras de saber", se reemplazan con disposiciones del conjunto de las relaciones en que consiste la "vida material", a saber, lo que Marx llama "modos de producción". 
La dialéctica materialista supuestamente desarrollada por Marx supondría, en este caso, el concepto del movimiento interno del test de control de cada "figura": en el seno de cada modo de producción se produciría cierto desarrollo de las "fuerzas productivas materiales" que, en cierto momento, supondría un riesgo para el propio modo de producción, puesto que las relaciones en que éste se basa serían una traba para el desarrollo de las fuerzas productivas espoleadas en su seno.

El modo de producción sería, para Marzoa $(2003,233)$ la "estructura económica". Sin embargo, el concepto de "estructura" de este autor no coincide con el de Ludwig Von Bertalanffy, alma mater de la Teoría General de Sistemas (Bertalanffy, 1976), ni con el concepto de estructura que, de modo implícito, maneja la ciencia, ni tan siquiera con los autores más significativos de la filosofía de la ciencia (Bunge, 2007) sino una versión idealista del mismo (en el sentido que se atribuye al concepto de "idea platónica"). Parece que el concepto de estructura en el pensamiento de este autor está tomado del estructuralismo, y se parece más al de los autores que confunden estructura con sistema (Althusser, 2010; Giddens, 1984), que vendría a ser algo así como confundir el territorio por el que transitamos con el mapa de éste. Nos dice el autor (loc cit) que entiende, por estructura, “...un complejo no empírico, sino construido idealmente (sic), con elementos de naturaleza asimismo ideal, en el que estos elementos no están yuxtapuestos unos a otros, sino implicados unos en otros, todo ello de modo que el complejo contiene sus propias leyes de movimiento internas y sus propias posibilidades de variación." Si eso fuera cierto, las relaciones de producción serían relaciones imaginarias y, por ende, el trabajo sería solamente una actividad mental. Marzoa no se da cuenta de que existe un referente para lo que él llama "estructura", y que en lenguaje marxiano son las relaciones de producción (que son las que se dan en un modo de producción determinado). De hecho, su concepto implícito de sistema (del que formaría parte dicha estructura) se parece bastante al que la TSD proclamaría años más tarde (Oyama, 2020) y, en el cual, la estructura (que dicha autora llama "metáfora", término que hace extensivo a todo concepto científico), es el sistema mismo; mismo malentendido en el que incurre la, así llamada, “filosofía de sistemas" (László, 1972), que, no obstante, recibiera el beneplácito del autor de la TGS. 
Marzoa añade (loc cit) que "una estructura se realiza en unos hechos". Consecuentemente, según su definición idealista de "estructura", supone que una vez pensada por algún filósofo (seguramente solipsista) la estructura se materializa. El autor "aclara" este punto, aduciendo que la estructura económica "...es aquella tal que los hechos que la realizan (sic) son todos materiales". Bien, ya sabemos que para Marzoa "realizarse" y "hacerse material” son la misma cosa en el ámbito "económico”. Y prosigue “...entendiendo ahora por hechos materiales aquellos que pueden y deben ser constatados con la exactitud propia de las ciencias de la naturaleza y entendiendo por las ciencias de la naturaleza la física matemática.” Bien, cabe observar que la física supone la matemática aplicada (por tanto, "física matemática" es una redundancia gratuita) y, además, hay otras ciencias de la naturaleza que también usan la matemática (la cual es el lenguaje universal de las ciencias). No queda claro qué son, para Marzoa, los "hechos materiales", ni por qué deben ser referidos a la "física matemática". Además, por lo que sabemos, tanto dicha terminología como, obviamente, tal planteamiento idealista es ajeno al discurso marxiano.

Según esta interpretación de Marx la "estructura económica" es el "modo de producción". Veamos esto con mayor detalle: la estructura es el conjunto de relaciones de los elementos de un sistema, por tanto, la estructura económica sería el conjunto de las relaciones de producción y, a fortiori, de cambio; pero esto no puede constituir el modo de producción, ya que en éste se hallan incluidos los elementos integrantes del sistema, y, de esta guisa, el modo de producción sería el sistema mismo (tal como el modo de producción capitalista es el sistema capitalista).

A un modo de producción determinado le corresponde un "edificio" de "ideas" y "formas" que expresa cómo dicho modo de producción se entiende a sí mismo, que es lo mismo que decir cómo aparece ante sí mismo, lo cual no coincide con lo que es en sí mismo. En este punto Marzoa no quiere usar la palabra alienación (aunque la haya descrito tangencialmente) para referirse a esa deformación de la realidad, porque para él es un concepto superado propio del "Marx joven" que, además, supondría la inclusión de un nuevo elemento que Marzoa no 
puede, de ningún modo, aceptar: el sujeto. Consecuentemente, si todo es estructura, solo hay relaciones "en sí mismas", o sea, sin los elementos que las mantienen, por tanto, sin sujetos. Marzoa sigue con su presentación de un Marx reverente ante Hegel, por lo que no puede tener su propio planteamiento, sino tan sólo “...una posición alternativa frente a Hegel” (loc cit). Que se sepa, Marx no necesitaba a Hegel para nada, ni tan solo para contraponerse a él; lo que sí es cierto es que Marx no toleraba el menosprecio ilegítimo de los "superadores” de Hegel hacia el pensamiento de éste, tal como manifestó claramente en el Epílogo a la segunda edición:

Mi método dialectico es por su fundamento no solo diferente del hegeliano, sino su contrario directo. Para Hegel el proceso del pensamiento, al que bajo el nombre de Idea transforma incluso en un sujeto autónomo, es el demiurgo de lo real, lo cual constituye sólo su manifestación exterior. En mi caso, a la inversa, lo ideal no es más que lo material transpuesto y traducido en la cabeza del hombre.

Hace casi treinta años que critiqué el lado mistificador de la dialéctica hegeliana, en una época en la que aún era la moda del día. Pero precisamente cuando componía el primer tomo de Das Kapital, los impertinentes, soberbios y mediocres epígonos que hoy tienen la gran palabra en la Alemania instruida, se complacen en tratar a Hegel como el bueno de Moses Mendelssohn a Spinoza en tiempos de Lessing, esto es, como a «perro muerto». Por eso me profesé abiertamente discípulo de aquel gran pensador, y hasta coqueteé aquí y allá, en el capítulo sobre la teoría del valor, con el modo de expresión que le era característico. La mistificación que sufre la dialéctica en manos de Hegel no impide en modo alguno que él sea el primero en exponer de un modo abarcante y consistente sus formas generales de movimiento. La dialéctica queda bocabajo en manos de Hegel. Hay que revolverla para descubrir el núcleo racional en el místico tegumento. (Marx, 1976)

Para nuestro autor, el ámbito en el cual se pone de manifiesto esa "posición alternativa" respecto de Hegel es el de la historia universal, es decir “...el ámbito total de la dialéctica" (loc cit). Marzoa olvida, con esa asunción, el hecho de que Marx siempre fue extremadamente 
cuidadoso con el uso del concepto dialéctica. En su descripción historiográfica, Marzoa sigue el patrón "Marx joven-Marx maduro” y sitúa el punto de inflexión en 1859, debido no a un “... mero desplazamiento del interés central, sino que tiene que ver con los términos en los que se produce el efectivo desarrollo del proyecto" (loc cit). Decir esto y afirmar que la obra de Marx tenía una lógica interna que escapaba a la voluntad de su autor es la misma cosa.

\section{Estructura a priori como sistema}

Nuestro analista de Marx se reafirma en su (siendo benévolos) malentendido: "Volvamos sobre el concepto modo de producción o estructura económica ( $\mathrm{sic}$ ) en los términos en que lo hemos definido unas líneas más arriba", es decir, tomando "estructura" por "sistema". Ahora Marzoa se refiere al "Marx de El capital” (Marzoa, 2003, 234), según el cual “...lo definido en esos términos no es universal alguno, sino algo que ocurre una sola vez y de lo que sólo hay un caso" (loc cit). El hecho de que haya una "estructura" en el sentido de Marzoa, y que dicha estructura "se realice íntegramente en hechos materiales, es decir, que sea económica [...] es un fenómeno único". No es ningún secreto que en Das Kapital Marx se centra en lo que él llama la lógica interna del sistema que analiza, que no es otro que la sociedad capitalista; sin embargo, eso no implica que se olvide de la lógica histórica que lleva a la formación de dicho sistema, como lo demuestran sus estudios sobre lo que él llamaba la acumulación originaria (Marx, 1976) así como su manifiesto interés por los procesos de transición entre sistemas. Por otro lado, en la dialéctica de la mercancía (a partir de la forma simple de valor) queda subsumida toda la historia de la mercancía, que implica, al contrario de lo que cree Marzoa, buena parte de la historia de la humanidad (aunque expuesta, de modo abstracto, en su lógica dialéctica).

Sorprendentemente, Marzoa da un giro copernicano en su exposición, y, sin mencionarlo explícitamente (o sin darse cuenta) asume la diferencia (que antes había negado) entre “sistema” y "estructura”; veámoslo: “... el solo hecho de que haya eso, de que haya modo de producción y estructura económica en el sentido fuerte de ambas nociones ( $\mathrm{sic}$ ), caracteriza ya suficientemente de qué modo de producción y de qué estructura económica se trata" (loc

Volumen 2. Número 1. Enero - Junio 2022 
cit). Lo que nos queda por saber, y que quizás nos diera la pista de por qué ahora ha captado la diferencia, es qué entiende el autor por "sentido fuerte de ambas nociones".

La pista la hallamos más adelante: Marzoa necesita, para defender su interpretación, que el "modo de producción moderno" no sea un caso particular del concepto más general "modo de producción"; sino que ocurra lo contrario, a saber, que "modo de producción moderno" sea la denominación del proceso único del caso, y que "modo de producción" sea una derivación de éste. El autor argumenta su tesis como sigue: "la justificación de que en la exposición figure este abstracto es ya sólo la de que las referencias a cosas situadas fuera del ámbito "moderno" forman parte de un modo u otro de la construcción del "modo de producción moderno", o sea, no se trata de que poseamos un concepto universalmente aplicable, sino justamente de que no lo poseemos y por eso estamos abocados a emplear una extrapolación a la que no podemos dar el carácter de tesis" (loc cit). Va de suyo que cuando uno cree que las estructuras (inmateriales, es decir, simplemente pensadas) se realizan en unos hechos materiales y eso es lo que determina cómo es la realidad, en vez de ser al revés, es decir, que las estructuras ideales no son más que la forma en la que concebimos las estructuras reales, que, como ya se ha dicho, son las relaciones entre elementos de sistemas, puede dejar de distinguir entre la realidad material y la versión de ésta que se trata de exponer mediante la argumentación, de tal modo que, al final, sea la última la que determine la primera. A partir de este punto, se pueden proferir genialidades tales como que el lenguaje construye la realidad y, una vez asumido esto, se puede sostener cualquier tesis sin sonrojarse, como puede verse a continuación: "El proyecto de Marx ha pasado a ser el de una construcción del fenómeno (sic) modo de producción moderno" (loc cit). En primer lugar, y como es ampliamente conocido, Marx no era idealista ni fenomenólogo (nunca se le habría ocurrido llamar "fenómeno" a un proceso). En segundo lugar, el modo de producción moderno no es otro que el modo de producción capitalista, un proceso que es propio de la sociedad capitalista, cuya función esencial es la acumulación de capital; los ítems mencionados son hechos y procesos materiales y objetivos (solamente pueden ser fenómenos desde una perspectiva idealista). 
Lo que, resumiendo y simplificando, viene a decir Marzoa, es que la sociedad moderna proyecta su autoimagen a las otras etapas de la historia, y que esa proyección solamente sirve para su autodescripción; así, solamente existe un concepto: el del modo de producción moderno (todo lo demás son adaptaciones de este concepto a las extrapolaciones históricas). En beneficio de Marzoa, hay que reconocer la posibilidad de que algunos autores hayan incurrido en tal supuesto, pero no es el caso de Marx, como puede comprobarse leyendo con detenimiento el primer tomo de Das Kapital.

Ese arbitrario paralelismo con Hegel lleva a Marzoa a forzar las cosas, hasta el punto de meter a Marx en unos berenjenales que le son totalmente ajenos, todo para terminar diciendo que en vez de todas las "figuras” ahora sólo habrá una: “...el querer referirse a un ser no reductible al concepto ( $\mathrm{sic}$ ) ha obligado a prescindir de la totalidad (sic)" (loc cit). El autor sigue empecinado y adjudica a Marx la renuncia al punto de vista de la totalidad con tal de asumir el legado dialéctico de Hegel "de un modo más esencial” que antes (Marzoa, 2003, 235).

Nuestro autor no tiene ningún problema en sostener lo contrario de lo que el propio Marx decía sobre su metodología: "Es manifiestamente falso que Marx describa, por ejemplo, la sociedad de su tiempo (sic). El trabajo de Marx es estrictamente constructivo a partir de algo que el pensador encuentra, pero que en ningún momento es un hecho empírico (sic).”

Lo que Marx “encuentra” al estudiar la sociedad moderna son procesos y hechos empíricos, los datos sobre los cuales constituyen el material de investigación, tal y como explica en su Epílogo a la segunda edición de Das Kapital:

"...el modo de exposición debe distinguirse formalmente del modo de investigación. La investigación tiene que apropiarse detalladamente el material, analizar sus diferentes formas de desarrollo y rastrear su vínculo interno. Sólo cuando se ha consumado ese trabajo se puede representar adecuadamente el movimiento real. Si se consigue esto y la vida del material se refleja idealmente, puede parecer como si se estuviera ante una construcción a priori." (Marx, 1975, 18-19) 
Por de pronto ya sabemos que Marzoa pasa por alto dicho parágrafo, y cae en la "trampa" sobre la que el mismo Marx advierte: en vez de ver en la exposición la descripción de los hechos y procesos reales, se ve la apariencia (es decir, el fenómeno) como una construcción $a$ priori. Para reforzar su argumento, nuestro autor se pregunta en qué sentido podría ser un hecho empírico el que las cosas, en general, sean mercancías; olvida que esta constatación, entre otras, no pertenece a la fase de investigación propiamente dicha, sino a su exposición, motivo por el cual le aparece como algo que Marx construye a priori. Marzoa incurre en otro error al imputar a Marx una lectura de la objetividad (o del "ser de la cosa") trivial: a saber, lo constitutivo de la realidad sería la posibilidad cuantitativa de cambio de cualquier cosa por cualquier otra; esta afirmación contradice directamente lo afirmado por Marx en su exposición del contenido de la forma relativa de valor: "Para averiguar cómo está inserta en la relación de valor entre dos mercancías la expresión simple de valor de una mercancía hay que considerar por de pronto esa relación con completa independencia de su aspecto cuantitativo" (Marx, 1975, 57). Esto puede resultar extremadamente paradójico, máxime si el lector no ha seguido el hilo de la argumentación de Marx desde el inicio (lo cual incluye los prólogos y epílogos).

A partir de la constatación que las cosas, en tanto que pertenecientes a la sociedad capitalista, son mercancías, Marx demuestra (Marzoa, 2003, 235-236) que la relación de valor entre las mercancías "...sólo es posible si hay una magnitud que se encuentra en todas las cosas, simplemente en cantidades diferentes, y demuestra también que esa magnitud se constituye por cuanto el sistema mismo efectúa la operación consistente en tomar todo el trabajo [...] que tiene lugar en él como uno solo del que sólo hay cantidades diversas", es decir, reduciendo la actividad productiva a "trabajo abstracto". Nuestro autor acaba de traicionar (acertadamente) su tesis original, puesto que afirmar que Marx demuestra todo eso es admitir que la contrastación de las hipótesis (surgidas a partir del manejo de un cúmulo de datos empíricos) que mueven sus investigaciones es certera. 


\section{Alienación alienada}

Veamos cómo nuestro autor se refiere a la alienación sin mencionarla: “...también demuestra [Marx] que es esencial al sistema el que la cantidad de tal "trabajo abstracto" que hay en cada mercancía no se manifieste en el propio funcionamiento del sistema como cantidad de trabajo abstracto, sino sólo mediante las relaciones cuantitativas de cambio entre unas y otras mercancías, y que la universalidad de esas relaciones de cambio sólo es posible si del conjunto de las mercancías se segrega una con la función de que los valores-de-cambio de todas las mercancías se expresen en cantidades de esa única" (loc cit). Pues bien: ¿qué nos dice este párrafo, sino que una de las normas ocultas del "juego", a saber, que nuestra actividad ser reduce a trabajo abstracto, no se puede conocer mientras se está "jugando" al "juego de la normalidad"? (por decirlo de algún modo). A continuación, nuestro autor se refiere a otra demostración de Marx: a saber, que la coherencia del sistema depende de que haya una mercancía cuyo consumo produzca más valor que el que tenía originalmente, y así, se cierra el círculo, ya que volvemos al trabajo abstracto (o, mejor dicho, a la mercancía fuerza de trabajo).

Según Marzoa, la descripción por parte de Marx de que un sistema en el que las cosas en general son mercancías, y la demostración de que este tipo de sistema no puede ser sino uno en el que haya dinero, capital y compraventa de fuerza de trabajo, implica “...que no se están describiendo hechos, sino produciendo (sic) una estructura”, pero, además, “...lo que se está estableciendo se llama la estructura económica de la sociedad moderna" (Marzoa, 2003, 236). Es decir, según nuestro autor lo que hace Marx es inventar el sistema capitalista. No satisfecho con tamaño despropósito, nuestro autor sigue adelante: “...no puede haber estructura económica de algún otro ámbito histórico que la sociedad moderna [...ni...] puede haber estructura [...] sin que ella sea del tipo que hemos definido como económica" (Marzoa, 2003, 236-237). Vamos a ver: siendo así que la estructura es el conjunto de relaciones entre los elementos de un sistema, y siendo así que cualquier sistema donde existan relaciones de cambio es un sistema económico en cualquier sistema en el seno del cual existan éstas existirá, también, estructura económica (Aristóteles, por ejemplo, ya estudiaba la estructura económica

Volumen 2. Número 1. Enero - Junio 2022 
de las sociedades de su época). Por otro lado, es manifiestamente falso que no pueda existir otro tipo de estructura que no sea la económica; forzar tal implicación mutua (hay estructura sí y solo sí es económica) lo que hace, en realidad, es invalidar el argumento. Los elementos de una estructura económica, además de mantener relaciones económicas entre ellos, mantienen otros tipos de relaciones: familiares, profesionales, administrativas, emocionales, etc. Consecuentemente, hay tantas estructuras como tipos de relación. Lo que sí se puede afirmar con certeza es que, en el sistema capitalista, la estructura más fuerte es la económica.

Lo que, dicho de forma simple sería la superación de la alienación, es decir, el reconocimiento de que lo que tenemos por lo normal no lo es en absoluto (por la trivialidad de que una normalidad cuyo presupuesto sea la ignorancia de cómo son las cosas en realidad no puede ser considerada como "normal"), y que tras ese mundo de apariencias se esconde una verdad que, por decreto, no deberíamos conocer, en Marzoa aparece como lo más esencial de la deuda de Marx con Hegel, y se refiere a ello del siguiente modo: “...el concepto hegeliano exige que sea la propia figura examinada la que comporte el patrón de medida del poner a prueba y precisamente en el sentido de que la figura de saber examinada, aun sin saber que lo hace, diferencia, frente a ella misma considerada como lo verdadero, un en qué consiste la verdad $\mathrm{y}$, desde el momento en que hay esta diferencia, hegelianamente ya está dicho que lo en principio verdadero quedará desautorizado (sic) por el comparecer de su en-qué-consiste-laverdad en el sentido de que a éste era inherente no aparecer como el en qué consiste la verdad de aquel saber precisamente, sino como un en sí" (Marzoa, 2003, 237). El en sí y el para sí: la caverna de Platón desde fuera y desde dentro.

\section{La figura única}

Nuestro autor no se queda corto en filigranas para "argumentar" su versión constructivista de Marx: lo primero que hace es dar por sentado que, al analizar el sistema capitalista, Marx abandona su visión dialéctica de la historia, y que para él la historia se convierte en "una única figura". El análisis de Marx, para nuestro autor, queda relegado a mostrar como “... la proyección de un patrón de medida y el poner a prueba se piensa precisamente en relación con 
ese patrón de medida, el cual ciertamente incluye como uno de sus aspectos el desarrollo de las fuerzas productivas, pero concebido dentro de algo más amplio y radical, que constituye el substitutivo fuerte de aquello del edificio de ideas y formas" (Marzoa, 2003, 237). Consecuentemente, y según Marzoa, ahora para Marx todo se reduce al capitalismo y a la imagen que proyecta de sí mismo (el "substitutivo fuerte"). El autor "aclara" que "...decimos substitutivo fuerte en dos sentidos a la vez: en primer lugar, en el de que, frente a la vaguedad del concepto substituido, se trata ahora de algo que puede ser establecido rigurosamente y de lo cual puede hacerse ver también rigurosamente, a partir de la estructura económica, cómo ello es en efecto el concepto de la verdad que la estructura económica comporta, cómo para la propia estructura económica tiene que ser un en sí, etc." (Marzoa, 2003, 237-238). Como es manifiesto, Marzoa intenta describir aquí la alienación sin mencionarla, confundiendo, además, los conceptos de estructura y de sistema (en realidad se está refiriendo a éste, pese a que lo llama “estructura”). La segunda parte de la justificación: “...en segundo lugar, también fuerte en el sentido de que, a diferencia de lo que ocurría con el edificio de ideas y formas, de lo que ahora se establece puede hacerse ver cómo ello y precisamente ello es el patrón de medida en la puesta a prueba de la figura" (Marzoa, 2003, 238). A lo que se refiere nuestro autor con el edificio de ideas y formas es al entramado jurídico-político-cultural-etc. que se erige sobre una "base" económica dada (una concepción marxiana que siempre se interpretó mal; como el tan difundido error de que la base consistiría en las relaciones de producción y la superestructura sería la ideología ad hoc); por lo demás, la "puesta a prueba" sería el llevar el sistema sus últimas consecuencias: a saber, la república democrática.

A continuación, Marzoa expone su versión de cómo este proceso tiene lugar en Das Kapital. "a lo que la figura pone como su en qué consiste la verdad es inherente [...] el que ello no aparece para la figura misma como su propio en qué consiste la verdad, sino como en si", (Marzoa, 2003, 238). En otras palabras: el sistema (la "figura") tiene una imagen distorsionada de sí mismo (su "en sí"), que no se corresponde con cómo es en realidad (su "en qué consiste la verdad"). Lo que nuestro autor no nos dice es que esto vale para todas las etapas por las que pasa le evolución de la forma de valor (desde la forma simple hasta la forma dinero) y que, consecuentemente, aunque la alienación que domina la sociedad capitalista sea la más 
"fuerte", también se da en otras formas de organización social (por lo menos en las que han sucumbido a la imposición de la forma de valor en la estructura velada que soporta la imagen de la "realidad").

Además, Marzoa tiene una visión cuantitativa de algo que para Marx es eminentemente cualitativo: lo esencial, para Marx, es que se "congele" la substancia humana en "paquetes" de "tiempo abstracto", no el proceso en el cual esto se lleva a término (el cual, por supuesto, también investiga). Lo que es esencial para Marx no es el hecho de que para medir el valor de cosas distintas haya que reducirlas a un factor común (cosa que no es ninguna novedad), sino que se admita la posibilidad de que las cosas contienen "gelatina" de substancia humana. Pero la admisión de todo esto haría tambalear el "edificio de ideas y formas" que nuestro autor está erigiendo sobre la base de una versión demasiado sesgada (y simplificada) del pensamiento marxiano.

Detrás de su "cuantificación” de Marx se esconde el motivo oculto de la argumentación de Marzoa: “...si el que las cosas sean remisibles a cantidades de una misma magnitud comporta no ciertamente que las cosas sean cantidades de una misma magnitud, pero sí que sean matemáticamente tratables, calculables, ocurrirá que esta calculabilidad y sus consecuencias será considerada como inherente al ser de las cosas; éste estará constituido, pues, por la calculabilidad, o sea, por la racionalidad científico-técnica. Nos encontramos aquí con la peculiar fundamentación marxiana de cierto rasgo de la Edad Moderna con el cual ya nos hemos encontrado, que el operar de esa estructura ha referido siempre ya las cosas a cantidades de una única magnitud, que ésta es el trabajo abstracto o trabajo igual, y que, a la vez, a esta reducción es inherente el que ella no se expresa sino en el modo de las relaciones de cambio de unas cosas con otras, es decir, no se expresa directamente en términos de cantidades de trabajo igual, sino en términos de cantidades de unas mercancías y cantidades de otras mercancías. Dicho de otra manera: la sociedad moderna asume que las cosas son remisibles a cantidades de una única magnitud, pero no asume eso como una asunción suya, de la sociedad moderna, como como algo que ha de poder hacerse con las cosas, por lo tanto, como algo cuyas implicaciones son supuestos acerca del ser de las cosas" (Marzoa, 2003, 238-239). De 
modo análogo, cuando respiramos somos conscientes de que el aire entra en nuestros pulmones, pero no de que nuestras células adquieren oxígeno.

Nos había dicho Marzoa que el edificio de ideas y formas había quedado atrás, sin embargo, al intentar describir el contenido de la ideología como la subsunción de lo cualitativo en lo cuantitativo se le escapa un componente esencial de dicho edificio: "[el] postulado de la igualdad de los hombres, que es la noción fundamental del derecho (sic). Tal postulado de igualdad implica considerar toda diferencia, y por lo tanto todo contenido, como accidental, como algo esencialmente ajeno; todo contenido es cosa o posibilidad de cosa y frente a él la relación consiste en la posibilidad de alienarlo, relación que llamamos propiedad y que es el tipo básico de relación jurídica con cosas" (Marzoa, 2003, 239). El uso de estos dos conceptos: "derecho" y "jurídico" debería estar justificado y argumentado, puesto que pertenecen a un ámbito del discurso que, según el autor, ya hemos "superado”. Entonces ¿por qué los usa en este contexto en el cual carecen de significado? ¿No será que, en realidad, todo ese metadiscurso no ha sido más que un espectáculo pirotécnico que se ha visto interrumpido por la abrumadora lluvia que ha empezado a caer desde los nubarrones de la "superestructura"?

Además, si estamos inmersos en una única "figura” ¿cómo es que Marzoa emplea no sólo los conceptos (como hemos visto antes) sino también el lenguaje de las "figuras" precedentes, como cuando aduce la trivialidad de que "la mercancía es llevada al mercado"? (loc cit). La "figura" del caso no es otra que el mercado (es decir, la sociedad [o sistema] capitalista), por tanto, todo es mercancía y todo el contexto es el mercado; nadie puede "llevar" nada al "mercado", porque todo lo que se "produce" nace en su propio seno. Resulta extraño que Marzoa no se percate de que Marx, en Das Kapital, sincroniza lo diacrónico, para presentarlo todo en un mismo "escenario", pero sin pretender que esto signifique (como pretende Marzoa) el abandono de la perspectiva histórica.

"La racionalidad científico-técnica y la república democrática son los dos aspectos de lo que la sociedad moderna proyecta como su concepto de la verdad" afirma Marzoa (loc cit). Sin embargo, ambos desiderata no son más que ideas nebulosas que se perciben como espejismos

Volumen 2. Número 1. Enero - Junio 2022 
en el horizonte de lo cotidiano. No hay un camino trazado para alcanzarlos, ya que no existe un concepto claro de cómo deberían ser. Simplemente están ahí para convencernos de que vamos hacia algún "escenario" mejor; que la historia sigue adelante y que algún día las "cosas" serán de otra manera y que por ello "vale la pena" seguir viviendo y luchando, en el marco de lo existente (y de lo percibido como tal). Otra función reguladora que cumplen estos "iconos" del sistema es la de evitar la tentación del cuestionamiento; podemos criticar el capitalismo, denunciar sus males, etc. pero no podemos cuestionar la ideología, es decir, las normas del juego, más que nada porque no sabemos realmente en qué consiste la ideología (cuando "llegamos al mundo" ya entramos a jugar a un juego que tiene las normas ya establecidas de antemano). En otras palabras: no podemos desalienarnos porque la alienación es nuestro estado natural.

Según nuestro autor, "la estructura ( $\mathrm{sic}$ ) pone como parte de su concepto de la verdad el postulado de igualdad, base del derecho. Ciertamente ni ese postulado [ni] ninguna otra cosa exige que los hombres sean realmente iguales. El problema no es que la estructura, la misma que segrega el postulado de igualdad, no haga realmente iguales a los hombres; el problema es que comporta estructuralmente una determinada y central desigualdad" (Marzoa, 2003, 239-240). La desigualdad a la que se refiere Marzoa consiste en el hecho de que existen distintos tipos de relación con el capital: por un lado, hay quienes lo poseen y acumulan, mientras que por el otro existen los que lo producen al venderse a sí mismos como mercancía. El sistema funciona, pues, mediante la tensión entre ambos subsistemas constituyentes. Sin embargo, el motivo de "las libertades" sigue sonando alegremente. Marzoa lo describe así: "no por ello la libertad civil tiene que ser falsa, ni hasta aquí se ha visto nada por lo que tenga que ser restringida; lo que ocurre es que cada ejercicio de la libertad requiere contenidos, los contenidos son cosas, es decir, mercancías, y la estructura sólo funciona sobre la base de una muy determinada desigualdad en la posesión de las mismas. Sucede entonces que el Estado, ciertamente, defiende el derecho de todos por igual, pero el derecho de todos por igual sólo tiene lugar en cuanto proyectado por una estructura que exige una muy determinada desigualdad en cuanto a si se está o no en situación de hacer uso del derecho" (Marzoa, 2003, 240). Ciertamente, donde dice "mercancías" debería decir “capital”, puesto que las mercancías 
están al alcance de cualquiera, por la trivialidad de que el sistema precisa que así sea para continuar funcionando. El estado basado en el sufragio universal y las libertades de comunicación refleja la contradicción implícita en el sistema en el que está inserto, funcionando como un aparato separado que escapa al control democrático directo (que es el único que puede garantizar lo que se supone que se debe garantizar). Esta contradicción sistémica la describe nuestro autor tal como sigue: "entre que la sociedad moderna necesita de la república democrática, porque lo que la república democrática expresa son asunciones efectivamente inherentes al funcionamiento de la estructura [léase "el sistema"], y que la sociedad moderna tiene que ponerse en guardia contra eso mismo que ella necesita, no hay según Marx síntesis alguna; sólo arreglos coyunturales (loc cit). Lo que equivale a decir que el único modo de salir de este círculo vicioso es rompiéndolo.

Marzoa extiende esa contradicción a lo que él llama la "racionalidad científico técnica": “...el concepto de la verdad propio de esta figura postula la calculabilidad como inherente al ser de las cosas [...] al concepto de la verdad propio de la sociedad moderna le es inherente el postulado de que no hay límite absoluto a la productibilidad o productibilidad-suprimibilidad o dominabilidad de las cosas. Sin embargo, el propio examen marxiano de la estructura pone de manifiesto tanto la necesidad que, en efecto, el modo de producción moderno tiene de lanzar el efectivo incremento de esa dominabilidad, la racionalización científico-técnica, como también el modo, asimismo estructural, en que esa misma racionalización tiene que ser frenada para que la estructura económica no se vea amenazada" (Marzoa, 2003, 240-241). Uno de los mecanismos típicos de frenado son las crisis. Otro, los cambios de "paradigma" político-económico (como el triunfo absoluto del neoliberalismo). El sistema debe protegerse "sistemáticamente "a sí mismo de aquello que proclama como su propia esencia. La "racionalidad" debe ser, en cierta medida, "irracional". 


\section{Revolución}

Marzoa entra en autocontradicción al tener que reconocer que, al final, la estructura no era algo conceptual, construido a priori por Marx, sino que, en tanto que la "puesta-a-prueba de la figura considerada [...] se sitúa en el terreno de la historia real" (Marzoa, 2003, 241). Así, todo lo que se dijo más arriba sobre el abandono por Marx de la historia en la construcción de la nueva "figura", ahora queda en entredicho, máxime cuando, según el propio autor, dicha "puesta-a-prueba" consiste en que la humanidad lleva la idea que el sistema tiene de sí mismo (lo que Marzoa designa como su "en-qué-consiste-la-verdad") hasta las últimas consecuencias. Eso ya lo decía Marx, pero, para nuestro autor, la vuelta a la "realidad material” es cosa de la humanidad: “[esta] operación revolucionaria [...] se realiza toda ella, pues, con criterios producidos como propios por la sociedad moderna misma, y los agentes que realizan tal operación lo hacen desde su condición (única en la que tienen lugar) de momentos estructurales de esa misma sociedad" (Marzoa, 2003, 241-242). O sea que, las personas, que solo existen como "momentos estructurales", hacen la revolución con criterios producidos por ellas mismas (la sociedad moderna). Aparte de lo poco revelador de este párrafo, el autor debería precisar qué entiende por "momentos estructurales", puesto que equiparar una persona a un "momento" es sumamente reduccionista, siendo así que, además, un "momento" es una acotación arbitraria del tiempo y, en este caso, del tiempo de una estructura a la que se confunde con el propio sistema. Con esta perspectiva, las personas no serían ya elementos del sistema, sino que serían entidades (aún por identificar) muy acotadas temporalmente y perdidas en la maraña de las relaciones que se dan entre los elementos del mismo.

"Si la operación llega a estar totalmente realizada, entonces ya no hay estructura económica, o sea, ya no hay sociedad moderna, y, por lo tanto, a lo que haya a partir de ahí no cabe ya referirse con ninguna de las categorías que sólo se han definido rigurosamente en el examen de esa figura, categorías que son todas las que se han definido rigurosamente; por lo mismo, ahí termina también el proyecto; éste no va más allá de la sociedad moderna; sólo reconoce internamente la finitud de ella" (Marzoa, 2003, 242). Efectivamente, Marx no realizó ningún

Volumen 2. Número 1. Enero - Junio 2022 
diseño de cómo sería (o debería ser) la sociedad nacida de la superación del modelo actual, porque no veía lícito proyectar sobre el futuro nuestros estrechos parámetros conceptuales en lo tocante a la estructura de la sociedad. Por lo tanto, la revolución (es decir, el reemplazo del sistema vigente por otro completamente nuevo, distinto y mejor) lleva a un territorio ignoto, en el cual no puede existir otra opción que la de hacer camino al andar. Las categorías válidas para el modelo anterior dejan de serlo por la trivialidad de que las relaciones sistémicas que describían ya no existen (ese era uno de los motivos por los que Marx se abstenía de hacer “futurología”). Sin embargo, en todo proceso evolutivo se mantienen los elementos viables de lo superado; para Marx serían la automatización y la comunicación... y parece ser que, por el momento, sigue siendo así.

\section{Referencias}

Althusser, Louis (2010). Para leer El Capital, SXXI.

Aristóteles (1987). Política. Madrid: Gredos.

Bertalanffy, L. V. (1976). Teoría General de Sistemas. Ciudad de México: Fondo de Cultura Económica.

Bunge, M. (2007). A la caza de la realidad. Barcelona. Gedisa.

Giddens, Anthony (1984). The Constitution of Society: Outline of the Theory of Structuration. Polity Press.

Hegel, G. W. F. (1974). Ciencia de la Lógica. Buenos Aires: Solar-Hachette.

László, Ervin. Introduction to Systems Philosophy. Routledge, London 1972. 
Marzoa, F.M. (1983). La filosofia de "El Capital". Madrid. Abada Editores. (2003) Historia de la Filosofia. Madrid. Akal.

Marx, K. (1976). El Capital. Barcelona: Grijalbo.

Oyama, Susan (2000). The Ontogeny of Information. Duke University Press. 